Monatsschrift für Geburtshülfe u. Gynäkologie 1909;29:631

\title{
Eduard Martin
}

\section{in memoriam.}

Am 22. IV. 1809 ist Eduard Martin in Heidelberg geboren; er starb am 5. XII. 1875 als Leiter der Berliner Universitäts-Frauenklinik.

Von J. Gh. Stark in Jena vorgebildet, sah Eduard Martin in Naegele seinen Lehrer, in dessen Klinik er einige Zeit gearbeitet hatte. In Jena habilitiert, 1846 Prof, ordinarius, wurde er 1858 nach Berlin berufen. Aus seiner J enenser Klinik ist Frankenhäusser als Professor hervorgegangen, aus der Berliner Olshausen, Gusserow, v. Winckel, Fasbender, Löhlein, A. Martin.

Eduard Martin muss als einer der Begründer der modernen Gynäkologie genannt werden. Er machte es zur Voraussetzung seiner Über-siedelung nach Berlin, dass ihm eine gynäkologische Abteilung in der Charitó neben der geburtshülflichen Klinik in der Dorotheenstr. 5 einge-richtet wurde. Ihm gebührt weiter das Verdienst, die Gynäkologie in innige Beziehung zur pathologischen Anatomie und zu den biologischen Forschungen gebracht zu haben, indem er seit 1866 hierfür an seiner Klinik selbständige Abteilungen schuf (D. Hausmann, Karl Ruge).

A. Martin. A. Rosthorn. 